\title{
Inside the Metropolis: the Articulation of Spanish Metropolitan Areas into Local Labor Markets
}

\author{
José M. Feria ${ }^{\mathrm{a}}$, José M. Casado-Díaz ${ }^{\mathrm{b}}$ \& Lucas Martínez-Bernabéu ${ }^{\mathrm{c}}$ \\ ${ }^{\text {a }}$ Department of Geography, University Pablo de Olavide, Seville \\ 41013, Spain \\ ${ }^{\mathrm{b}}$ Department of Applied Economic Analysis and Institute of \\ International Economics, University of Alicante, PO Box 99, \\ Alicante E-03080, Spain \\ ${ }^{\mathrm{c}}$ Institute of International Economics, University of Alicante, PO \\ Box 99, Alicante E-03080, Spain
}

Published online: 26 Aug 2015.

José M. Feria, José M. Casado-Díaz \& Lucas Martínez-Bernabéu (2015): Inside the metropolis: the articulation of Spanish metropolitan areas into local labor markets, Urban Geography 36(7), 1018-1041

DOI: $10.1080 / 02723638.2015 .1053199$

To link to this article: http://dx.doi.org/10.1080/02723638.2015.1053199

\begin{abstract}
This article delimits local labor markets (LLMs) in order to analyze the structure and internal organization of Spanish metropolitan areas. LLMs are defined as self-contained and cohesive areas in terms of commuting flows. Unlike the conventional approach to polycentrism based on the analysis of commuting flows that begins with the identification of subcenters, this analytical strategy does not assume that a specific structure exists, and is compatible with the relationship between places of work and residence having other location and spatial organization patterns. The analysis is carried out on three different scales of detail linked to three self-containment levels for the LLMs delimited and three population groups (total, males and females). The results show that metropolitan areas are complex, fuzzy, multidimensional spaces, where the conditions of spatial organization are manifested in different ways depending on the parameters and variables used.
\end{abstract}

Keywords: metropolitan areas, local labor markets, commuting, spatial organization.

\section{Introduction}

The basic nature of contemporary urban form and function is metropolitan, and the major issue of understanding the metropolis' morphology and structure has been on the research agendas of many social sciences (geography, economics, sociology, etc.) for almost 
a century. In recent decades, increasingly formalized and broader spectrum approaches have been added to the now classic, required reading reference works of the first half of the 20th century (Burgess, 1925; Hoyt, 1939, Harris and Ullman, 1945) which, nonetheless, were fundamentally based on single case studies (Conzen and Greene, 2008) and contained no small amount of intuition. These new approaches consider not only modern metropolises' increase in size, but mainly their increasing complexity (Bertaud, 2004; Hanlon et al., 2006; Lee, 2007; Kneebone, 2009; Filion and Kramer, 2012; Paulsen, 2012).

In recent years a large part of the exploration of new metropolitan organizational and structural conditions is based on the notion of polycentrism (Champion, 2001a; Kloosterman and Musterd, 2001; Boix and Trullén, 2012), and, significantly, its use has spread to the analysis of both European (e.g., Meijers, 2005; Riguelle et al., 2007; Roca et al., 2009) and North American metropolitan spaces (e.g., Anderson and Bogart, 2001; Parr, 2004). However, not all authors use the notion of polycentrism unequivocally: it has for example been applied to different analytical scales (Sarzynski et al., 2005) and with normative purposes (Davoudi, 2003). Obviously the key task of empirical polycentrism analysis is to identify subcenters or alternative centers, which for the most part tend to be defined as areas of concentrated economic activity and, especially, of employment, outside the CBD or central city. Unlike the above studies, which adopt a morphological focus, authors like Bourne (1989), Gordon and Richardson (1996), Aguilera (2005) and Roca et al. (2009) identify subcenters by adopting a functional focus based on flow analysis, specifically the analysis of commuting.

This second group of studies therefore ties in with the traditional analysis of commuting as an indicator of urban structure (Pisarski, 2006; Sohn, 2005). Commuting is, without doubt, the core variable that defines metropolitan areas and other functional area typologies in urban settings in today's world. The availability of information on commuting 
in the census, its materiality (as a physical journey) compared to other types of interrelationships not subject to the constraints of distance, its condition as a recurrent process and the fact that it links labor markets and household locations all justify its relevance as a key variable for understanding the functional organization of metropolitan space. As a consequence of its relevance, many research studies have used the commuting variable to address the new form and structure of the metropolitan city with a wide range of focuses, from pioneering studies, such as O'Connor and Maher (1979) on Melbourne, to the most recent that analyze commuting patterns and urban form and structure (Burger et al., 2011; Modarres, 2011), not forgetting others that link commuting and residential location, or mobility (Cervero and Wu 1997; Senecal et al., 2013).

Given this broad range of commuting based approaches to metropolitan spatial organization, is there any room to develop a different analytical strategy to expand our knowledge about its nature and configuration? In response to this question, the present article explores a new approach to investigate the structure and internal organization of metropolitan areas in greater depth. This is a strategy grounded in the analysis of commuting patterns, and which links to approaches to polycentrism with a functional (vs. a morphological) focus. However, unlike these, the object of analysis in our proposal is not to identify subcenters and their areas of influence, but to study the functional organization of metropolitan space without any prior assumption as to its structure. To achieve this, the present article proposes an analytical strategy to address the structure of metropolitan areas based on the identification of the local labor markets (LLMs) into which they are articulated. These LLMs are identified as regions that from a functional point of view are externally self-contained and internally integrated as far as commuting patterns are concerned, and are delineated through a method that does not depart from the identification of cores. This is, therefore, a strategy that combines the two types that the literature on the delimitation of functional areas most clearly 
identifies: metropolitan areas and LLMs. In such literature, metropolitan areas are understood as complex systems of which LLMs are a fundamental part that defines their internal organization. Apart from this new strategy, the study makes a contribution on two fronts. On the one hand, on the methodological level it is not restricted to only one parameter of the commuting variable, but explores the alternative configurations that can be identified depending on changes in the self-containment thresholds and differences according to gender. On the other hand, unlike a large number of prior studies on the topic, the analysis is not limited to single cases, but is of all the metropolitan areas of an entire country, Spain.

From the methodological point of view, the focus proposed for analyzing the structure of metropolitan areas is a regionalization procedure which assigns each of the basic units that comprise the metropolitan area (in this case, municipalities) to one or other of the LLMs. Thus, the starting point is, in principle, Boolean logic focused on membership to a certain region or not. However, although this type of categorization -regionalization- is extremely useful for classifying and planning space, it is much less so for understanding the way it functions and how it is organized, as most spatial processes are not subject to Boolean logic (Gale and Atkinson, 1979). This is the case of the variable which is specifically focused on here, commuting, which refers to a state of flows and indeterminacy based on whether each territorial unit is related to a given region to a specific degree (as stated in Shearmur and Motte, 2009, for example). One possible approach for this modeling of spatial organization is the theory of fuzzy sets (Zadeh, 1965), in which the make-up rules (inclusion, union, intersection, complement, relation) offer a series of alternative criteria for approaching the regionalization issue (Plane, 1998; Feng, 2008; Heikkila and Wang, 2010; Feria et al., 2011). We propose an alternative modeling procedure through the consideration of three different scales of analysis, each of which is related to a specific value of the degree of selfcontainment that characterizes the LLMs that are defined. A municipality's or a census tract's 
membership of a region is therefore no longer governed by the Boolean 0-1 rule, but it is defined by a range of degrees of membership to different regions connected to the different scales and parameters of analysis adopted. This analytical strategy also enables the observable structures to be considered separately when the working population is no longer regarded as a homogenous whole and attributes are considered that enable it to be segmented into two or more groups (defined according to sector of activity, occupational group, or age or gender group, for example).

The paper is organized as follows: the following section reviews some of the characteristics and differences between metropolitan areas and LLMs as functional regionalizations. Next the data and methods used are justified and described. The fourth section presents and discusses the results, and in particular how Spanish metropolitan areas are articulated into LLMs on the three territorial scales analyzed, both for the overall population and for the segmentation of this group with regard to one of the possible dimensions already mentioned, the gender of the employed. As is the norm, the last section summarizes the main conclusions drawn.

\section{Background}

The need to address the spatial limitation of the new urban-territorial realities arises from the unsuitability of the traditional administrative-based units to cope adequately with the current scale at which social and economic processes work. Two of the "families" of functional areas that have developed in this respect are: firstly, one whose greatest exponent is the definition of metropolitan areas, which focuses on delimiting and analyzing the new scale of the urban environment. In short, it consists of the identification of areas which are articulated around simple or combined centers and the territorial units that comprise their respective areas of interdependence (Berry et al., 1970; OMB, 1998). The second type of 
functional area corresponds to LLMs, areas where labor supply and demand interact on the local scale, and which can therefore be defined for the whole of the country rather than only for exclusively urban zones (Casado-Díaz and Coombes, 2011).

The definition of the metropolitan area, when understood as its geographic delineation according to the nature of the urban processes that it includes, was not originally a merely academic or theoretical question, but the result of legislative or purely practical aspects, such as the collection, treatment and dissemination of statistical information. The reasons that justify the foregoing are none other than the result of the recognition of metropolitan areas as the fullest expression of the urban phenomenon in contemporary societies. The city that we know today is a city that is in no way similar, in either its scale or configuration, to the city that historically characterized traditional societies. Thus it is the metropolitan processes where the new condition of "the urban" and the real scale and organization of the true contemporary city are evident in the clearest and most widespread form. The most basic meaning of metropolitan area is no more than a polynucleated urban area (Erikson, 1986; Batty, 2001) that forms a unitary residential and labor market that simultaneously reflects both the increased scale of living space (Courgeau, 1988) and the economic agents' different spatial strategies (Scott, 2008). This results in relatively complex processes and spatial structures that depend on both the unique characteristics of each urban reality -territorial, historical, etc.- and the intensity and range of these processes. However, the result in any case is the general emergence of a new urban form that clearly differs from the historical compact city.

An effort has been made in many countries, and over several decades in some, to delimit this new urban scale with greater accuracy, and on that basis gather, present and subsequently analyze and evaluate its dimension and the way it works. There are many possible criteria and variables that can be used to approach this, from the simplest of 
demographic size or of an administrative nature, to others that are much more complex and based on functional relationships, not forgetting those that include morphology -or densityrelated elements. Logically, this is not the place to present such a wide range of approaches (Champion, 2001b; OECD, 2012), but there is a degree of agreement in the literature that the most identifiable, coherent and powerful of these lines of work on this issue is that which uses commuting as the key variable to define metropolitan areas (Horner, 2004). Since it was first used in the United States in the 1950 Census to define Standard Metropolitan Areas, commuting has come to be in the present day the fundamental benchmark for processes to define these new urban spatial realities (OMB, 1998). The use of commuting has subsequently spread, with specific variants, to a large number of widely different countries, in geographical and socio-economic terms. These are the cases of, for example, France (Julien, 2000), Italy (Martinotti, 1991), Canada (Murphy, 2003), Mexico (INEGI, 2004), GEMACA's study for countries in Western Europe (Cheshire and Gornostaeva, 2002), Eurostat's analyses of the European Union as a whole (Urban Audit, 2008), and OECD (2012) for the OECD countries.

In Spain, there is no official or institutional delimitation for this urban universe (metropolitan areas) of either a political and administrative nature, or for purely statistical purposes. However, in recent years a number of articles have appeared in the academic sphere that put forward specific proposals: Feria (2008 and 2010) and Roca et al. (2012). In these articles, metropolitan areas are delimited on the basis of the commuting variable and their findings differ, basically, because of the different values given to the parameters used in the various procedures. It should nevertheless be highlighted that a great deal of convergence can be seen between the findings in more recent studies (Feria, 2010; Roca et al., 2012), and between them and those for Spain in broader studies, such as the previously-mentioned OECD study (OECD, 2012). 
For its part, delimiting LLMs is a very frequent exercise in many countries, especially in Europe, both in the academic sphere and, most notably, in public administrations (OECD, 2002). There is a generalized agreement about the theoretical concept of LLMs: the delimitation of the territorial area in which suppliers and demanders of work meet on the local scale. However in practice there are so many specific proposals for making the concept operational that in the field of public administrations, for example, there is no method that has been officially adopted by more than one country. All the methods share several characteristics: the geography of the resulting LLMs covers the territory comprehensively, there is no overlapping (all the basic territorial units belong to one, and only one, LLM) and they are based on the commuting variable. The objective of all these methods, recognized explicitly in some cases and tacitly in others, is to identify areas (groups of municipalities, counties or other base units) that are highly self-contained in terms of commuting (what Goodman, 1970, called external perfection) and that, at the same time, are made up of base units between which high levels of interaction are produced in terms of this same variable (internal cohesion). A critical review of the various methodologies available in international practice in this field, including the scarce references to the Spanish case, can be found in Casado-Díaz and Coombes (2004 and 2011) and Casado-Izquierdo and Propin-Frejomil (2008).

The logic behind the two groups of functional areas reviewed, metropolitan areas and LLMs, is different. Whilst the former are based on systematizing dependency relationships and the existence of hierarchies in urban environments where the population and economic activities are relatively highly concentrated, more important in the second is the systematization of relationships between equals based on methods that, broadly speaking, do not involve the identification of centers and hinterlands, but rather the analysis of the relationships that exist among all the units under consideration, at least as far as the longest 
standing methods are concerned. The differences in the approach (top down vs. bottom up) and the degree of coverage of the territory being considered (only the most densely populated in the first case and the whole of the territory in the second) are two of the elements that clearly distinguish between the two groups of methods (Casado-Díaz and Coombes, 2004). However, from a deeper point of view there are much greater differences than this. Metropolitan areas are multifaceted in nature (areas encompassing complex territories where material and infrastructure development, residential spaces, centers of activity, etc. are articulated with a wide array of intense flows of people, goods, services and information). LLMs, however, are specifically designed for the study of labor phenomena in local areas, as they are based on the definition of boundaries that seek to faithfully reflect how the labor market is articulated in territorial terms (the relationships between those who offer employment and those who seek it, and their effect on the way that wages and other labor conditions are set, amongst other issues). Labor-related phenomena are only one of the aspects that are encompassed in the concept of the metropolitan area. Nevertheless, given the significance and versatility of metropolitan areas, in countries where the two concepts metropolitan areas and LLMs- are defined, the two are often understood as equivalents in the most urbanized regions. This is the case in the U.S., for example, where the geography of the LLMs is composed of the metropolitan (and micropolitan) areas and an additional procedure is used as an alternative in the most rural (or less intensely urban) regions in order to comprehensively cover all U.S. territory (U.S. Department of Labor, 2013).

\section{Data and method}

The analysis is conducted of the metropolitan universe as defined by Feria (2008) (Figure 1) in an adaptation of the procedure developed in the US by the Office of Management and Budget for the United States census (OMB, 2000) to the case of Spain. This 
is a standard procedure adapted to international practices and its formalization is set out in the algorithm in the appendix. The data used in the analysis are taken from the 2001 Population Census and are the latest data available for Spain. They were sourced from the Spanish National Statistics Institute (Instituto Nacional de Estadística; INE). This is a group of origindestination matrices that show the flow of workers that journey from one municipality in Spain to another on a daily basis to carry out their work tasks ${ }^{1}$. Three of these matrices are used in this paper: one for total employed population and two more that split said population by worker gender.

[Figure 1 about here]

From the practical point of view, the proposed method is based on analyzing the degree to which the metropolitan areas considered behave as unitary labor markets. The analysis involves two tasks: firstly, verifying the level of self-containment of each of the areas compared to the rest of the territory (external perfection); and secondly, analyzing their internal cohesion. For their internal cohesion to be studied, any separate LLMs that might exist within the metropolitan areas are delimited, if possible. This enables the degree to which each metropolitan area behaves as an integrated whole to be analyzed: in short, the extent to which the base territorial units, the municipalities, are sufficiently interlinked to be considered integral parts of a single metropolitan LLM or are articulated into a variety of submarkets that are, in turn, externally perfect and internally cohesive.

With regard to the first task, self-containment, this is in reality a twofold condition, since it must be achieved both in terms of the so-called (Coombes et al., 1986) supply side

\footnotetext{
${ }^{1}$ It should be mentioned that the building blocks in the Spanish census for the commuting variable are municipalities and not census tracts. This prevents very useful detailed analyses being carried out, especially of large municipalities.
} 
self-containment (the percentage of residents in the municipality/market who are in employment within its boundaries) and also demand side self-containment (the percentage of workplaces that exist in the municipality/market that are occupied by workers who reside within it).

Regarding the second aspect, the identification of LLMs within metropolitan areas, the most recently developed method to delimit the so-called Travel to Work Areas (TTWAs) in the United Kingdom (Coombes, 2010) has been chosen here to identify the LLMs into which the different metropolitan areas are articulated. One of the most relevant features of the TTWA procedure (and one of the main differences from many of the alternative methods available) is the fact that the initial groupings of municipalities are reconsidered during the process following a strategy designed to ensure that the regionalization procedure is not constrained by the initial decisions, which thus helps results to be reached that are closer to the optimum. Despite relevant advances having been made in this area in recent years using other sophisticated techniques (see, for example, Martinez-Bernabeu et al., 2012), the decision was taken to use this procedure for several reasons. Firstly, identifying the TTWAs in the United Kingdom has undoubtedly been the most relevant exercise of this type from the perspective of public policies and has been successfully replicated in numerous countries, thus confirming its transferability. This procedure is based on an analysis of the functional relationships between areas and complies with the rest of the requisites suggested by Eurostat (1992). Finally, and very importantly for the purpose of this analysis, the method has been substantially simplified with respect to earlier versions. This has enabled arbitrary decisionmaking regarding the parameters used in earlier versions to be eliminated, turning it into one of the easiest to understand.

The TTWA method (which is formally described in the appendix) consists of two steps that are repeated until all the municipalities under consideration are grouped into LLMs 
that meet the requisites for commuting self-containment (no minimum size restriction was considered for the LLMs that were identified). Given that the purpose of this paper is to analyze the internal structure of Spanish metropolitan areas regarding how they are configured into LLMs, the decision was taken to adopt three different scales of study and therefore three alternative thresholds were set for minimum self-containment. These thresholds include a minimum requirement level (50\%), which is undoubtedly low for any unit of analysis to be considered functionally independent, and also two values with a certain tradition in the literature on this topic: $66.7 \%$ (the minimum required in the last revision of the British TTWAs) and 75\%, which was considered by Smart (1974) as a compromise level, an intermediate point between the minimum requirement and the maximum possible. It should be borne in mind that the higher the minimum self-containment requisite demanded, the lower the number of LLMs identified.

The analysis of the internal configuration of metropolitan areas into LLMs is completed in the article by adding another dimension: the separate consideration of males and females. The intention is for this to be simply an example, an empirical exploration of how segmenting the whole of the working population allows further levels of complexity to become obvious, since the scope of the paper is not a gender analysis of the problem. Other alternative segmentations for this same exemplification could have included: education, age or sector of activity, for example. The combination of three minimum self-containment thresholds and three population groups gives a total of nine metropolitan labor submarket delimitations in all, and these are presented in the following section under the heading of internal cohesion.

Basically two precedents to the method used in this paper can be cited as having some connection: the analyses of the Spanish case conducted by Roca et al. (2012) and that of the Mexico Valley Metropolitan Area by Casado-Izquierdo (2012), although substantially 
different formal procedures were used in both cases. The analysis conducted by Roca et al. (2012) was based on the calculation of the indicator used in Coombes et al. (1986) to assign a weight to the intensity of the link between pairs of areas or regions in terms of commuting. According to the indicator, municipalities are merged to form so-called proto systems, urban systems, metropolitan areas and metropolitan regions; it is, therefore, a strategy which is almost the opposite of the one followed here. It also needs to be highlighted that the identification of self-contained LLMs in metropolitan areas is considered, in this case, only from what Coombes et al. (1986) call supply side self-containment: the proportion of the resident working population that is employed within the boundaries of the area, and the complementary point of view, namely demand side self-containment (the percentage of jobs located in the area that are occupied by residents of the area) is not taken into account. The proposed procedure could therefore give rise to LLMs being identified that are only partially self-contained. For his part, Casado-Izquierdo (2012) analyzes the structure of the Mexico Valley Metropolitan Area by identifying LLMs defined using the method used for delimiting TTWAs in the 1980s and 1990s (Coombes et al., 1986). This procedure has the disadvantage of including an additional 13 parameters compared to the procedure used in this article, where only the scale of analysis has to be set; i.e., the self-containment threshold required for each of the LLMs to be considered as such. The existence of a great number of parameters makes the whole operation complex, as a small variation in any of these can result in great differences in the structures of the LLMs that are identified, thus making any conclusions drawn very tentative. Also, as the study only refers to a single large metropolitan region, the findings cannot be easily extrapolated to larger areas with a greater variety of realities.

\section{Results and Discussion}

\section{External Perfection}


Figures 2 and 3 give initial results as to the way that Spanish metropolitan municipalities are configured in terms of commuting. The indicator on the municipal level in Figure 2 is the proportion of employed people who work in the municipality of residence (what was previously referred to as supply side self-containment). This is, therefore, an indicator that is independent of the specific chosen configuration of metropolitan areas. The variable in Figure 3, however, does depend on the metropolitan boundaries considered, as for each municipality it is calculated as the proportion of employed residents that work within the metropolitan area of which the municipality forms part.

[Figure 2 about here]

[Figure 3 about here]

Figure 2 shows that the degree of functional self-containment of the municipalities that make up the largest Spanish metropolitan areas is situated for the most part between $25 \%$ and 50\% (in the cases of Madrid, Barcelona, Valencia, Bilbao and Gran Canaria). Functional dependence is somewhat smaller on average in Gijon and Saragossa and in the municipalities of the large Andalusian metropolitan areas (Seville, Malaga and Cadiz-Jerez), where municipal self-containment more frequently stands at between $50 \%$ and $75 \%$. When the focus of the functional analysis is extended to the metropolitan boundaries (Figure 3), the level of self-containment of most of the municipalities in practically all the metropolitan areas considered exceeds $95 \%$. This means that in the most extreme cases only $5 \%$ of the municipality's employed population works outside the metropolitan boundaries and only $5 \%$ of the jobs that exist are taken by workers from other nonmetropolitan municipalities. The exceptions are Pontevedra and Santiago de Compostela, in Galicia, Donostia in the Basque Country, and Lleida, Girona and Manresa in Catalonia, all of which are minor metropolitan 
areas. As is logical, the levels of linkage with the respective metropolitan areas are relatively lower in the municipalities that are further away from the foci of their respective areas (this is the case of the far south of the Madrid metropolitan area and the metropolitan fringes of Barcelona and Bilbao, for example).

\section{[Table 1 about here]}

Table 1 gives a more detailed breakdown of the results in Figure 3. It shows that the metropolitan areas delimited by Feria (2008) have high levels of self-containment in terms of commuter flows compared to external areas (the median is almost $94 \%$ for the total population and approximately one percentage point less and one percentage point more, respectively, when males and females are considered separately). They therefore meet one of the conditions for being considered as LLMs: external perfection. Linked to the above, there is a great functional balance in terms of the ratio between jobs and people employed in each of the areas. As will be remembered, the other condition set by Goodman (1970) referred to a high degree of internal cohesion, or in other words the existence of intense functional links between the units that comprise a potential LLM. This condition implies that the area as a whole can be considered a cohesive market in which multiple demanders and suppliers of employment are interrelated; this is, therefore, an area in which it is possible to change one's place of residence without having to change one's job, and vice versa.

\section{Internal Cohesion}

The main objective of the analysis is to identify the LLMs that exist inside the metropolitan areas on the three analytical scales adopted, while also adding another dimension to the analysis: the consideration of males and females separately. 
The analysis provides noteworthy results for each of the thresholds used, showing, firstly, a logical inverse relationship between the level of self-containment required and the number of LLMs identified in the metropolitan areas, but revealing, secondly, a clear-cut structural pattern in the metropolitan areas' levels of articulation.

Table 2 summarizes the results with respect to the first point. It shows that the 46 Spanish metropolitan areas are subdivided into 394 LLMs when the total population is considered and a 50\% minimum level of self-containment is set for said LLMs. The figure falls when the requirements level is raised: 130 LLMs for a minimum $66.7 \%$ level of selfcontainment, and 69 when the threshold is set at $75 \%$. The median (mean) of the number of residents employed is a good indicator of how the scale varies when the exercise is conducted: compared to a figure of $112,865(226,264)$ employed people for the metropolitan delimitation, the values reached for the three alternative divisions into LLMs change to 2,491 $(26,416), 29,419(80,062)$ and $66,649(150,843)$ as the self-containment requirement is increased.

\section{[Table 2 about here]}

Leaving aside this logical statement, the results are more informative when the structural pattern drawn by these LLMs is scrutinized for each of the delimitations. When the self-containment requirements are high (75\%), what appears is a very high level of fit with the exact delimitations of the metropolitan areas (Figure 4). To be precise, four-fifths of the metropolitan areas cannot be divided into separate LLMs, as either the market that exists fully coincides with the metropolitan area, or in a few cases what can be seen is a dozen or so micromarkets formed of only one or two municipalities and that emerge solely due to their weak metropolitan links. The exceptions to this rule are either metropolitan areas that have been identified (Feria, 2013) as having a polycentric territorial nature (Cadiz-Jerez, Oviedo- 
Gijon-Aviles, Malaga-Fuengirola, Barcelona-Sabadell) or smaller areas with alternative municipalities to the central municipality that are powerful places of employment (Torrelavega in Santander metropolitan area, Molina de Segura in Murcia and Santa Lucia de Tirajana in Gran Canaria). Consequently, these exceptions aside, Spanish metropolitan areas are assimilators of large labor markets when the requirements for self-containment are high, in keeping with what was stated in the previous subsection on their external perfection.

[Figure 4 about here]

However, there is a substantial change when only the data for employed females are considered; patterns characterized by daily mobility that affects smaller volumes and, especially, shorter distances compared to those for males, result in metropolitan territory that is much more fragmented, with the 46 metropolitan areas defined for the total population split into a total of 113 LLMs (Table 2). In this case, the median for the employed population is 12,164 (and the mean of this variable is 38,193 ). What stands out is the fact that the difference between the number of LLMs identified for males and females is widely disproportionate in the different metropolitan areas (the most striking case is Madrid, where the ratio is 8:1 and, at the other extreme, the examples of Valencia and Gran Canaria, where the number of LLMs identified does not vary by gender on this level). These differences cannot be explained by the size and hierarchy of the metropolitan areas. However, they may be justified by the difference in their sectoral activity structure and their corresponding occupational distributions by gender.

When the self-containment requirement is set at the levels used in official delimitations, such as the British TTWAs (66.7\%), the number of markets that can be identified for the total population practically doubles, rising to 130 . A very different 
perspective is gained with this threshold compared to the previous threshold, as a careful analysis of the results shows the existence of consolidated separate LLMs in some of the metropolitan areas delimited and gives clear signs of internal decentralized articulation processes. This affects especially -and consistently- the two Spanish metropolitan regions (Feria, 2013), although there is no unequivocal direct relationship between the size of the metropolitan area and the degree of internal decentralization; so, although it is the second largest metropolitan area in the Spanish urban hierarchy behind Madrid, Barcelona not only presents a greater number of LLMs (eight in all), but these LLMs are also much larger and more robust, providing the area with an evident polycentric articulation ${ }^{2}$. In the case of Madrid, the area is configured as one large LLM centered on the capital with an extremely high level of self-containment (97.8\%), and five more with a self-containment of around 70\%: two mid-size (Aranjuez to the south and Guadalajara to the east), and three more with much smaller populations made up of a maximum of five municipalities.

[Figure 5 about here]

On the following hierarchical level (consolidated metropolitan areas, Feria, 2013) the metropolitan areas with populations of one million plus (Valencia, Seville, Bilbao and Malaga) are organized into LLMs, although the results for the Seville metropolitan area are slightly confusing, as the nine found that are differentiated from the central city are in reality minimarkets, with one or two municipalities located around the periphery of the metropolitan ring. This affects not so much the emergence of LLMs as how weakly these municipalities

\footnotetext{
${ }^{2}$ In the metropolitan delineation proposed by the OECD (2012) these LLMs are characterized as differentiated metropolitan areas. Historical reasons linked to industrialization patterns and geographical features associated with the area's peculiar topography explain this decentralized articulation.
} 
are embedded in the metropolitan area. Meanwhile, the LLMs that emerge with the $75 \%$ threshold in the polycentric areas or the areas with a second place of employment consolidate and expand, and other metropolitan areas also emerge in which the lines of relatively powerful LLMs are drawn: Castellon, Santiago de Compostela, Donostia, Vigo, Girona and Tarragona. These areas are on different levels of the metropolitan hierarchy, even the lower levels, and in general terms correspond to the model of a second center of employment that acts as an organizer of an alternative LLM.

When the distribution is analyzed by gender, a great disparity in the appearance of LLMs can once again be observed: around 100 for males and almost double that for females, for whom the number of LLMs is practically five times that of metropolitan areas (Table 2). However, despite the substantial increase in the number of LLMs identified, broadly speaking the structure remains the same when the female population is considered separately (Figure 6 and Table 3) and the median for the resident employed population changes to 2,380 (mean 20,749). To give an example, the Barcelona metropolitan area continues to be characterized by a high number of greatly balanced markets ( 11 for females compared to the 8 for the total population and 4 for males), while in the Madrid metropolitan area there is a large market centered on the capital and a higher number of LLMs (13) that are much smaller in size (many now composed of one or two municipalities), especially in the southeastern part of the area.

[Figure 6 about here]

[Table 3 about here]

Finally, if the requirement level considered for the self-containment of the LLMs identified is reduced even further, to $50 \%$, the metropolitan areas' internal articulation is 
atomized when the results are mapped: on this analytical scale Madrid, Saragossa and, to a lesser extent Valencia, are the metropolitan areas where a large LMM centered on the capital can still be seen to exist that draws together a large number of municipalities with very high functional dependency compared to other municipalities (as reflected in the low levels of self-containment recorded in Figure 2). Contrary to this pattern, a great deal of atomization can be observed in the other large metropolitan areas (Table 3) and in virtually all the remaining metropolitan areas, which is coherent with the levels of self-containment set out in Figure 2. This means that many of the municipalities integrated in the metropolitan areas reach the level of self-containment required to constitute unitary LLMs when they are individually considered and the threshold is set at values as low as 50\% (it should be remembered that this is, in fact, the only relevant requirement in this exercise, as no restriction has been included as to the minimum size of the LLMs generated). Once more this is a pattern that holds when the gender of the employed resident is considered: the considerable increase in the number of LLMs identified when the analysis is limited to females (a total of 483 for the 46 Spanish metropolitan areas) is rendered as the widespread atomization of the metropolitan LLM structure that, nonetheless, continues to be more balanced in the case of Barcelona than Madrid, as a large market can be clearly observed around Madrid. It should once more be stated that the differences in the number of LLMs identified for males and females are not in the same proportions in the different metropolitan areas. There are approximately twice as many female LLMs as male LLMs in Madrid, Barcelona and Oviedo-Gijon-Aviles, whereas the two are practically identical in Seville, Gran Canaria, Zaragoza, Cadiz-Jerez and, to a lesser extent, Valencia, Bilbao and Malaga.

\section{Conclusions}


The purpose of this paper is to analyze metropolitan areas as complex systems within which local labor markets are essential components that define their structure and internal organization. With this aim, the internal and external consistency of the metropolitan areas has been analyzed as LLMs in terms of the variable most commonly used in the literature: commuting. On the one hand these have been tested to verify whether they are self-contained entities and, on the other hand, their internal structure has been delineated in terms of highly self-contained LLMs.

To summarize, the analyses allow the conclusion to be drawn that the Spanish metropolitan areas are, at least according to the delineation proposed by Feria (2008), selfcontained labor markets compared to external areas (as when taken as a unit they all exceed very demanding thresholds regarding the percentage of "metropolitan" jobs taken by workers who reside within the metropolitan boundaries, and the percentage of "metropolitan" residents working within those boundaries); i.e., they achieve reasonable scores in what Goodman calls external perfection.

Secondly, very detailed commuting-based analyses have been conducted in order to explore the internal spatial structure of Spanish metropolitan areas in terms of LLMs and from the theoretical perspective that they are not closed and one-dimensional, but complex, with different levels and scales of organization. To carry out this task, three different selfcontainment levels have been used systematically for the LLMs and applied to the working population, both as a whole and by gender.

The results show that at a high level of requirement (75\%) there is evident symmetry between the metropolitan areas and the LLMs delimited (only one fifth of the metropolitan areas are divided into different LLMs), thus confirming assimilation between the two dimensions. The only exceptions to this rule are either metropolitan areas that have a settlement system that is clearly polycentric in nature, or smaller areas where there are 
alternative municipalities to the central municipality that are powerful alternative places of employment. Moreover, when a conventional requirement level (66.7\%) is applied, internal articulation patterns can be identified in LLMs within the metropolitan areas: 18 of the 46 Spanish metropolitan areas delimited can be identified as being articulated internally by consolidated LLMs (130 in all). The emergence and strength of the internal organization in the universe of Spanish metropolitan areas at this scale of analysis are explained by two vectors of interpretation. Firstly, logically, by the size and hierarchy of the metropolitan areas, with those on the first three tiers of the hierarchy (basically over 500,000 inhabitants) being articulated into consolidated LLMs. Secondly, it is the structure of the basic urban system of the metropolitan areas (for functional and geo-historical reasons) that result in nuances and differences and explain their greater or lesser tendency towards diverse forms of complex articulation, including polycentrism. The division of the metropolitan areas is considerably accentuated when the self-containment threshold is set at $50 \%$, since in this case 394 LLMs emerge. Separate LLMs appear in practically all the metropolitan areas at this threshold, but what is most interesting is that, whereas there has only been a moderate increase in the number of LLMs in those that previously presented a more obviously polycentric structure, the increase has been much greater in centralized structures, but comprised of minimarkets.

The second set of analyses, aimed at identifying LLMs, included an example of how dividing the working population according to one specific dimension results in structures with a marked difference. The attribute chosen here was the gender of the population, resulting in much greater compartmentalization in the case of females than in males, irrespective of the scale addressed (for the $75 \%, 66.7 \%$ and $50 \%$ self-containment levels the number of female LLMs identified within the 46 metropolitan areas was 113, 208 and 483, respectively). This result is logically related to the fact that commuting patterns for employed 
females are characterized by affecting smaller volumes and involving shorter distances compared to their male counterparts, although it is noticeable that the difference between the number of LLMs identified for males and females is widely disproportionate in the various metropolitan areas.

To summarize, this regionalization exercise based on the joint analysis of a number of different self-containment thresholds and by gender digs deeper into the internal spatial structure of Spanish metropolitan areas. Unlike closed, Boolean, one-dimensional approaches (for example: monocentric vs. polycentric models based upon the analysis of employment concentration), the results attest to complex, fuzzy and multi-dimensional spaces where the conditions of spatial organization are manifested in different ways depending on the parameters and variables used, in this case to define LLMs, and allow the nature of contemporary urban spaces to be better understood.

The limitations of the analysis relate to the data as well as to the regionalization methods and parameters used. Firstly, with respect to the timeframe, the most recent available when the study was done; it should be recognized that there may have been substantial changes in commuting patterns. Nonetheless, it should also be stated that the time reference is identical for the definition of the metropolitan areas and their LLMs, meaning that the relationships observed between the two sets of functional areas are genuine and correspond to the time when the data were collected. Updating with the 2011 Census data when they become available will enable these analyses to be repeated and the way that these relationships have evolved over time to be studied. Secondly, and as in any other research dealing with territorial issues, the analysis is subject to the so-called modifiable areal unit problem (MAUP), since the results are influenced by the scale and spatial configuration chosen (the specific set of boundaries for a given scale). The first of these problems is, in this case, mainly related to the level of self-containment required of the LLMs identified within 
the limits of the different metropolitan areas - the lower the level, the higher the number of submarkets and the more detailed the level of spatial aggregation. The second refers to the specific procedures used in the regionalization issue (the specific method for identifying metropolitan areas and LLMs) once a precise scale is adopted, since different methods could result in different ways of grouping the territorial building blocks for a given level of aggregation. With regards to the first issue, it must be acknowledged that using three alternative scales, as is done here, mitigates the problem, although obviously it does not eliminate it, since other specific scales could have been chosen. With regard to the so-called zoning problem, in both cases (metropolitan areas and LLMs) the international standard methods used in this study are those used by public administrations with a longer tradition (United States metropolitan areas and British Travel to Work Areas), and they are, without doubt, a benchmark for good practice in their field. The substantial differences according to population group considered should also be highlighted; in this study the only differentiation has been by gender, but this could be extended to other variables, such as age, sector of activity or level of education, to name but a few, and this would enrich the analyses and would be especially useful when formulating public policies. To conclude with the limitations of the study, more detailed analyses are required to dig deeper into the reasons that explain the differences between metropolitan areas, especially when the differences are found in areas on the same tier of the hierarchy that have similar base settlement structural systems. These include, for example, the broad disparity between metropolitan areas with respect to the number of female LLMs. References to unique geographical, historical, functional specialization etc. factors may help to explain certain specific points, but must be completed with more systematic studies, opening the focus up to other areas of study and including new variables and parameters that would enable any common patterns and the reasons for differences in metropolitan processes to be understood at one and the same time. 


\section{Acknowledgements}

[Reference to the project/funding source to be included here]. The funding source played no part in the study design; in the collection, analysis and interpretation of data; in the writing of the report; or in the decision to submit the paper for publication. 


\section{References}

Aguilera, Anne (2005). Growth in commuting distances in French polycentric metropolitan areas: Paris, Lyon and Marseille. Urban Studies 42(9), 1537-1547.

Anderson, Natham B. and Bogart, William T. (2001). The structure of sprawl: Identifying and characterizing employment centers in polycentric metropolitan areas. American Journal of Economics and Sociology 60, 147-169.

Batty, Michael (2001). Polynucleated urban landscapes. Urban Studies 38, 635-655.

Bertaud, Alain (2004). The Spatial Organization of Cities: Deliberate Outcome or Unforeseen Consequence? (Working Paper Number 2004-01). Berkeley, CA: Institute of Urban and Regional Development, University of California. Retrieved from http://alainbertaud.com/wp-content/uploads/2013/06/AB_The_spatial_ organization_of_cities_Version_31.pdf

Berry, Brian. J. L. Goohen, Richard and Goldstein, Sydney, (1970). Problems and perspectives of defining the metropolis. In Brian Berry and Frank Horton, editors, Geographic Perspectives on Urban Systems. Englewood Cliffs: Prentice Hall, 250276.

Boix, Rafael and Trullén, Joan. (2012). Policentrismo y estructuración del espacio: una revisión crítica desde la perspectiva de los programas de investigación. ACE 13, 2754.

Bourne, Larry S. (1989). Are new urban forms emerging? Empirical tests for Canadian urban areas. The Canadian Geographer / Le Géographe canadien 33, 312-328.

Burger, Martijn. J., de Goei, Bastian, Van der Laan, L. and Huisman, F. J. M. (2011). Heterogeneous development of metropolitan spatial structure: Evidence from communing pattern in English and Welsh city-regions, 1981-2001. Cities 28, 160-170. 
Burgess, Ernest W. (1925). The growth of the city: An introduction to a research project. In R. E. Park, E. W. Burgess, and R. D. McKenzie, editors, The City. Chicago, IL: University of Chicago Press, 47-62.

Casado-Díaz, José M. and Coombes, Mike (2004). Delineation of Local Labour Market Areas (LLMAs). Paper presented at NECTAR's Cluster 4 annual meeting 'Communications, labour markets and urban systems'. Alicante: Universidad de Alicante.

Casado-Díaz, José M. and Coombes, Mike (2011). The Delineation of 21st Century local Labour Market Areas: A critical review and a research agenda. Boletín de la Asociación de Geógrafos Españoles 57, 7-32.

Casado-Izquierdo, José M. (2012). La estructura policéntrica de los mercados laborales locales de la Zona Metropolitana del Valle de México. Investigaciones Geográficas, Boletín del Instituto de Geografía, UNAM 79, 97-118.

Casado Izquierdo, José M. and Propín Frejomil, E. (2008). Praxis internacional en el estudio de mercados laborales locales. Investigaciones Geográficas (MX) 65, 118-137.

Cervero, Robert and Wu, Kang-Li (1997). Polycentrism, commuting, and residential location in the San Francisco Bay area. Environment and Planning A 29, 865-886.

Champion, Anthony (2001a). A changing demographic regime and evolving polycentric urban regions: consequences for the size, composition and distribution of city populations. Urban Studies 38, 657-677.

Champion, Anthony (2001b). Urbanization, Suburbanization, Counterurbanization and Reurbanization. In Richard Padisson, editor, Handbook of Urban Studies. London: SAGE, 143-161.

Cheshire, Paul and Gornostaeva, Galina (2003). Cities and regions: Comparable measures require comparable territories. Cahiers de L'Aurif 135, 13-2. 
Conzen, Michael and Greene, Richard (2008). Introduction: All the world is not Los Angeles, nor Chicago: Paradigms, schools, archetypes and urban process. Urban Geography 29, 97-100.

Coombes, Mike (2010). Defining Labour Market Areas by analysing commuting data: Innovative methods in the 2007 review of Travel-to-Work Areas. In J. Stillwell, O. Duke-Williams and A. Dennet, editors, Technologies for Migration and Commuting Analysis: Spatial Interaction Data Applications. Hershey, PA: IGI Global, 227-241.

Coombes, Mike, Green, Anne E. and Openshaw, Stan (1986). An efficient algorithm to generate official statistical reporting areas: the case of the 1984 Travel-to-Work Areas revision in Britain. Journal of the Operational Research Society 37, 943-953.

Courgeau, Daniel (1988). Méthodes de Mesure de la Mobilité Spatiale. Migrations Internes, Mobilité Temporaire, Navettes. Paris: Institut National D’Études Démographiques.

Davoudi, Simone. (2003) European briefing: Polycentricity in European spatial planning: from an analytical tool to a normative agenda? European Planning Studies 11(8), 979999.

Erikson, Rodney A. (1986). Multinucleation in metropolitan economies. Annals of the Association of American Geographers 7(3), 331-346.

Eurostat (1992). Study on Employment Zones (E/LOC/20). Luxembourg: Office for Official Publications of the European Communities.

Feng, Zhigiang (2008). Fuzziness of Travel-to-Work Areas. Regional Studies 42, 1-14.

Feria, José M. (2008). Un ensayo metodológico de definición de las áreas metropolitanas españolas a partir de la variable residencia-trabajo. Investigaciones Geográficas 46, 49-68. 
Feria, José M. (2010). La delimitación y organización espacial de las áreas metropolitanas españolas: Una perspectiva desde la movilidad residencia-trabajo. Ciudad y Territorio. Estudios Territoriales 164, 189-210.

Feria, José M. (2013). Towards a taxonomy of Spanish metropolitan areas. Boletín de la Asociación de Geógrafos Españoles 63, 347-376.

Feria, José M., Oliveira, Gwendoline., Barrena, Eva and Ibañez, Eloy (2011). Cartographier les mobilités pour analyser l'organisation spatiale de l'Andalousie. Mappemonde 102.

Filion, Pierre and Kramer, Anna (2012). Transformative metropolitan development models in large Canadian urban areas: The predominance of nodes. Urban Studies 49, 22372264.

Gale, Stephen and Atkinson, Michael (1979). On the set theoretic foundations of the regionalization problem. In Stephen Gale and Gunnar Olsson, editors, Philosophy in Geography, Dordrecht: D. Reidel Publishing Company, 65-107.

Goodman, John F.B. (1970). The definition and analysis of Local Labour Markets: Some empirical problems. British Journal of Industrial Relations 8, 176-196.

Gordon, Peter and Richardson, Harry W. (1996). Beyond polycentrity: The dispersed metropolis, Los Angeles 1970-1990. Journal of the American Planning Association 62(3), 289-295.

Harris, Chauncy D. and Ullman, Edward L. (1945). The nature of cities. The Annals of the American Academy of Political and Social Science 242, 7-17.

Hanlon, Bernardette, Vicino, Thomas and Short, John R. (2006). The new metropolitan reality in the US: Rethinking the traditional model. Urban Studies 43, 2129-2143.

Heikkila, Eric J. and Wang, Yiming (2010). Exploring the dual dichotomy within urban geography: An application of fuzzy urban sets. Urban Geography 31, 406-421. 
Horner, Mark W. (2004). Spatial dimensions of urban commuting: A review of major issues and their implications for future geographic research. The Professional Geographer $56(2), 160-173$.

Hoyt, Homer (1939). The structure and growth of residential neighborhoods in American cities. Washington, DC: Federal Housing Administration.

Instituto Nacional de Estadística, Geografía e Informática (2004). Delimitación de las Zonas Metropolitanas de México. México: Secretaría de Desarrollo Social.

Julien, Philippe (2000). Mesurer un univers urbain en expansion. Economie et Statistique 336, $3-33$.

Kloosterman, Robert C. and Mustard, Paul (2001). The polycentric urban region: towards a research agenda. Urban Studies 38, 623-633.

Kneebone, Elizabeth (2009). Job Sprawl Revisited: The Changing Geography of Metropolitan Employment. Washington, DC: The Brookings Institution, Metropolitan Economy Series, Brookings Institution Metropolitan Policy Program.

Lee, Bumsoo (2007). Edge or edgeless cities? Urban spatial structure in U.S. metropolitan areas, 1980 to 2000. Journal of Regional Science 47, 479-515.

Martínez-Bernabéu, Lucas, Flórez-Revuelta, Francisco and Casado-Díaz, José M. (2012). Grouping Genetic Operators for the Delineation of Functional Areas based on Spatial Interaction. Expert Systems with Applications 39, 6754-6766.

Martinotti, Giuseppe (1991). La población de la nueva morfología social metropolitana. In J. Borja, M. Castells, R. Dorado and I. Quintana, editors, Las Grandes Ciudades en la Década de los Noventa. Madrid: Sistema, 65-141.

Meijers, Evert (2005). Polycentric urban regions and the quest for synergy: is a network of cities more than the sum of its parts? Urban Studies 42, 765-781, 
Modarres, Ali (2011). Polycentricity, commuting pattern, urban form: The case of Southern California. International Journal of Urban and Regional Research 35, 1193-1211.

Murphy, Peter (2003). Preliminary 2006 Census Metropolitan Area and Census Agglomeration Definition. Geography Working Paper Series, 2003-02. Ottawa: Statistics Canada. O'Connor, Kevin and Maher, Christopher A. (1979). Change in the spatial structure of a metropolitan region: Work-residence relationships in Melbourne. Regional Studies 13, 361-380.

OECD (2002). Redefining Territories: the Functional Regions. Paris: OECD Publishing. OECD (2012). Redefining “Urban”. A New Way to Measure Metropolitan Areas. Paris: OECD Publishing.

OMB (1998). Alternative approaches to defining Metropolitan and Nonmetropolitan Areas. Federal Register 63(244), 70526-70561.

OMB (2000). Standards for defining Metropolitan and Micropolitan Statistical Areas. Federal Register 65(249), 82228-82238.

Parr, John (2004). The polycentric urban region: A closer inspection. Regional Studies 38, 231-240.

Paulsen, Kurt (2012). Yet even more evidence on the spatial size of cities: Urban spatial expansion in the US, 1980-2000. Regional Science and Urban Economics 42, 561568.

Pisarski, Alan E. (2006). Commuting in America III: The Third National Report on Commuting Patterns and Trends. Washington, DC: Transportation Research Board. Retrieved from http://onlinepubs.trb.org/onlinepubs/nchrp/CIAIII.pdf

Plane, David A. (1998). Fuzzy set migration regions. Geographical and Environmental Modelling 2, 141-162. 
Riguelle, Francois, Thomas, Isabelle and Verhetsel, Ann (2007). Measuring urban polycentrism: A European case study and its implications. Journal of Economic Geography 7, 193-215.

Roca, Josep, Marmolejo, Carlos and Moix, Monserrat (2009). Urban structure and polycentrism: Towards a redefinition of the sub-centre concept. Urban Studies 46(13), 2841-2868.

Roca, Josep, Moix, Monserrat and Arellano, Beatriz (2012). El sistema urbano en España. Scripta Nova XVI(396), 1-35.

Sarzynski, Andrea, Hanson, Royce and Wolman, Hal (2005). All Centers Are Not Equal: An Exploration of the Polycentric Metropolis. GWIPP Working Paper Series (WP 015). Washington, DC: George Washington Institute of Public Policy. Retrieved from http://www.gwu.edu/ gwipp/papers/wp015.pdf

Scott, Allen J. (2008). Social Economy of the Metropolis. Oxford: Oxford University Press.

Sénécal, Gilles, Hamel, Pierre J., Collin, Jean-Pierre, Jastremski, Kathryn, Vachon, Nathalie and Lafortune, Marie-Ève (2013). Daily mobility and residential migration in the Montreal metropolitan region: The axis hypothesis. SAGE Open 2013(3).

Shearmur, Richard and Motte, Benjamin (2009). Do commutes bind Montreal's central and suburban economies? Urban Affairs Review 44(4), 490-524.

Smart, M.W. (1974). Labour Market Areas: Uses and definitions. Progress in Planning 2(4), 238-353.

Sohn, Jungyul (2005). Are commuting patterns a good indicator of urban spatial structure? Journal of Transport Geography 13, 306-317.

Urban Audit (2008). 2008 Conference on the State of European Cities: The Urban Audit. Brussels 10 June. 
U.S. Department of Labor (2013). Labor Market Areas 2013. Washington, DC: U.S.

Department of Labor, Bureau of Labor Statistics. Retrieved from http://www.bls.gov/lau/lmadir.pdf

Zadeh, Lofti A. (1965). Fuzzy Sets. Information and Control 8, 338-353. 


\section{Appendix - Delineation Procedures}

\section{Metropolitan Areas (MA)}

Inputs:

- matrix of commuting flows, $\mathbf{T}$, where $T_{i j}$ is the number of workers that commute from municipality i to municipality $\mathrm{j}$,

- vector of cores, $\boldsymbol{C}$, where $C_{i}=1$ if municipality $\mathrm{i}$ is a potential core and $\mathrm{C}_{\mathrm{i}}=0$ otherwise,

- vector of total inhabitants per municipality, $\boldsymbol{P}$,

- vector of municipalities that are provincial capitals, $\boldsymbol{H}$, where $H_{i}=1$ if it is a provincial capital and $H_{i}=0$ otherwise.

Note: Initially, all the municipalities with $P_{i}>100,000$ and provincial capitals with $P_{i}>50,000$ are considered as potential cores.

\section{Algorithm:}

Step 1: Aggregate municipalities to the cores: allocate (simultaneously) each non-core municipality $i$ to the potential core municipality c if $T_{i c}>100$ and $T_{i c} / R_{i}>0.2$ or if $T_{i c}>1,000$ and $T_{i d} / R_{i}>0.15$.

Step 2: Aggregate municipalities to the areas previously generated: allocate (simultaneously) each remaining noncore municipality i to the potential area $A$ if $T_{i A}>100$ and $T_{i A} / R_{i}>0.2$ or if $T_{i A}>1,000$ and $T_{i A} / R_{i}>0.15$, where $T_{i A}=\sum_{j \epsilon A} T_{i j}$.

Step 3: Discard small areas: each potential MA from the previous step whose core has fewer than 100,000 inhabitants and whose hinterland has fewer than 50,000 inhabitants is discarded.

Step 4: Reworking of the potential core list: remove the municipalities comprising discarded small areas from the initial list of potential cores, and consider as new potential cores each nonprovincial capital with more than 50,000 inhabitants that was not allocated to any area in the previous steps. 
Then repeat steps 1 to 3 and end.

\section{The Travel to Work Areas (TTWAs) algorithm}

Inputs:

- matrix of commuting flows, $\mathbf{T}$, where Tij is the number of workers commuting from municipality i to municipality $\mathrm{j}$,

- vector of total employed residents per municipality, $\boldsymbol{R}$,

- vector of total jobs per municipality, $\boldsymbol{J}$,

- parameters for the validity criteria: minimum self-containment, $S C_{o b j}$, and minimum size in employed residents, $R_{o b j}$ (in the original version a tradeoff relationship is established so that larger TTWAs are allowed to register lower SC levels; in this article $R_{o b j}=1$, which implies that no minimum size condition is applicable).

Note: In this article, for each metropolitan area the matrix of commuting flows is restricted to the municipalities inside said metropolitan area, but vectors $\mathrm{R}$ and $\mathrm{J}$ are related to the real values of each municipality within the commuting matrix for the whole of Spain.

Algorithm:

Step 1: Consider each municipality as a potential TTWA, A, and calculate the degree of validity ("X-function”)

$g(A)=\min \left\{1,\left[\sum_{i \epsilon A, j \epsilon A} T_{i j} / \max \left(\sum_{i \epsilon A} R_{i}, \sum_{i \epsilon A} J_{i}\right)\right] / S C_{o b j}\right\} \times \min \left(1, \sum_{i \epsilon A} R_{i} / R_{o b j}\right)$

Step 2: Take the TTWA with the lowest degree of validity. If it is a valid TTWA then end.

Otherwise, for each of the municipalities, i, that compose the invalid TTWA, calculate the interaction index with each of the remaining TTWA, A, as $\left.f(\mathrm{i}, \mathrm{A})=\left[\left(\sum_{\mathrm{j} \in \mathrm{A}} T_{i j}\right)^{2} /\left(R_{i} \sum_{\mathrm{j} \in \mathrm{A}} J_{j}\right)\right]+\left(\sum_{\mathrm{j} \in \mathrm{A}} T_{j i}\right)^{2} /\left(J_{i} \sum_{\mathrm{j} \in \mathrm{A}} R_{j}\right)\right]$.

Then reallocate each municipality i to the TTWA A that maximizes the interaction index and repeat this step. 
Tables

Table 1. Characteristics of the Spanish metropolitan areas

(indicators of functional balance and self-containment depending on the population group considered)

\begin{tabular}{lrrrrrrrr}
\hline & \multicolumn{3}{c}{ Ratio jobs/residents in employment } & \multicolumn{4}{c}{$\begin{array}{c}\text { Minimum (supply self-containment, demand } \\
\text { self-containment), } \%\end{array}$} \\
\hline Regionalization & Minimum & Median & Maximum & Mean & Minimum & Median & Maximum & Mean \\
\hline Metropolitan areas (total population) & 0.95 & 1.00 & 1.16 & 1.01 & 82.7 & 93.9 & 98.7 & 93.0 \\
Metropolitan areas (males) & 0.96 & 1.01 & 1.21 & 1.02 & 78.9 & 92.7 & 98.1 & 92.0 \\
Metropolitan areas (females) & 0.92 & 1.00 & 1.08 & 1.00 & 86.3 & 94.7 & 99.2 & 94.1 \\
\hline
\end{tabular}

NOTE: the minimum (supply self-containment, demand self-containment) is defined as the minimum value of all values obtained when calculating these two indicators: supply self-containment (the percentage of employed people resident in the metropolitan area that work within its boundaries) and demand self-containment (the percentage of jobs that exist in the metropolitan area that are taken by workers who reside in the municipalities that comprise the metropolitan area).

Source: prepared by authors using commuting data taken from the Census of Population and 2001. 
Table 2. Number and resident employed population of local labor submarkets by population group and minimum levels of self-containment considered (all Spanish metropolitan areas)

\begin{tabular}{|c|c|c|c|c|c|c|c|c|c|}
\hline & \multicolumn{9}{|c|}{ Minimum self-containment required of the local labor markets defined } \\
\hline & \multicolumn{3}{|c|}{$50 \%$} & \multicolumn{3}{|c|}{$66.70 \%$} & \multicolumn{3}{|c|}{$75 \%$} \\
\hline & \multirow[b]{2}{*}{$\begin{array}{l}\text { Number of } \\
\text { LLMs }\end{array}$} & \multicolumn{2}{|c|}{$\begin{array}{l}\text { Resident employed } \\
\text { population }\end{array}$} & \multirow[b]{2}{*}{$\begin{array}{l}\text { Number of } \\
\text { LLMs }\end{array}$} & \multicolumn{2}{|c|}{$\begin{array}{c}\text { Resident employed } \\
\text { population }\end{array}$} & \multirow[b]{2}{*}{$\begin{array}{l}\text { Number of } \\
\text { LLMs }\end{array}$} & \multicolumn{2}{|c|}{$\begin{array}{c}\text { Resident employed } \\
\text { population }\end{array}$} \\
\hline & & Mean & Median & & Mean & Median & & Mean & Median \\
\hline Total population & 394 & $26,416.60$ & $2,491.5$ & 130 & $80,062.7$ & $29,419.5$ & 69 & $150,843.0$ & 66,649 \\
\hline Males & 342 & $17,813.80$ & $1,854.5$ & 109 & $55,892.7$ & $23,303.0$ & 59 & $103,259.0$ & 42,028 \\
\hline Females & 483 & $8,935.51$ & 851.0 & 208 & $20,749.3$ & $2,380.0$ & 113 & $38,193.4$ & 12,164 \\
\hline
\end{tabular}

NOTE: minimum self-containment is the minimum value of two indicators: supply self-containment (the proportion of employed people resident in the area that work within its boundaries) and demand self-containment (the proportion of jobs that exist in the area that are taken by workers who reside in area).

Source: prepared by authors using commuting data taken from the Census of Population 2001. 
Table 3. Number of labor submarkets identified in Spanish metropolitan areas by gender and level of self-containment considered (in brackets: the number formed of less than three municipalities)

\begin{tabular}{|c|c|c|c|c|c|c|c|c|c|}
\hline & \multicolumn{3}{|c|}{$75 \%$} & \multicolumn{3}{|c|}{$66.7 \%$} & \multicolumn{3}{|c|}{$50 \%$} \\
\hline & $\begin{array}{l}\text { All people in } \\
\text { employment }\end{array}$ & Males & Females & $\begin{array}{l}\text { All people in } \\
\text { employment }\end{array}$ & Males & Females & $\begin{array}{l}\text { All people in } \\
\text { employment }\end{array}$ & Males & Females \\
\hline Madrid & $1(0)$ & $1(0)$ & $8(4)$ & $6(1)$ & $4(1)$ & $14(5)$ & $34(18)$ & $25(11)$ & $53(37)$ \\
\hline Barcelona & $2(0)$ & $1(0)$ & $4(0)$ & $8(0)$ & $4(0)$ & $11(1)$ & $23(8)$ & $16(5)$ & $32(14)$ \\
\hline Valencia & $1(0)$ & $1(0)$ & $1(0)$ & $6(3)$ & $5(2)$ & $8(3)$ & $14(9)$ & $15(8)$ & $20(14)$ \\
\hline Seville & $2(1)$ & $2(1)$ & $8(7)$ & $10(9)$ & $7(5)$ & $15(13)$ & $28(27)$ & $26(24)$ & $28(26)$ \\
\hline Bilbao & $1(0)$ & $1(0)$ & $4(0)$ & $3(0)$ & $3(0)$ & $5(0)$ & $12(4)$ & $11(1)$ & $18(10)$ \\
\hline Gijon-Oviedo-Aviles & $3(1)$ & $3(1)$ & $4(1)$ & $5(1)$ & $4(1)$ & $8(5)$ & $11(8)$ & $7(2)$ & $19(17)$ \\
\hline Malaga & $2(0)$ & $2(0)$ & $10(9)$ & $3(1)$ & $3(1)$ & $13(12)$ & $14(13)$ & $11(9)$ & $17(16)$ \\
\hline Gran Canaria & $2(0)$ & $2(0)$ & $2(0)$ & $2(0)$ & $2(0)$ & $3(0)$ & $4(1)$ & $4(1)$ & $4(1)$ \\
\hline Saragossa & $2(0)$ & $1(0)$ & $3(2)$ & $2(1)$ & $2(0)$ & $4(2)$ & $11(8)$ & $11(9)$ & $13(9)$ \\
\hline Cadiz-Jerez & $3(2)$ & $2(1)$ & $5(4)$ & $4(3)$ & $4(3)$ & $5(4)$ & $6(6)$ & $6(6)$ & $7(7)$ \\
\hline
\end{tabular}

NOTE: The figures at the top of the columns refer to the minimum level of self-containment required for a group of municipalities to be considered as a local labor market in a specific metropolitan area (rows). The minimum market self-containment is defined as the minimum value of two indicators: supply self-containment (the percentage of employed people resident in the market that work within its boundaries) and demand self-containment (the percentage of jobs that exist in the market that are taken by workers who reside within the market) Source: prepared by authors using commuting data taken from the Census of Population 2001. 


\section{Figure Captions}

- Figure 1. Delimitation of Spanish metropolitan areas.

Source: Feria (2008).

- Figure 2. Proportion of employed that work in the municipalities where they reside.

Source: prepared by authors using commuting data taken from the Census of Population 2001 .

- Figure 3. Proportion of employed that work in the metropolitan areas of which the municipalities where they reside form part.

Source: prepared by authors using commuting data taken from the Census of Population 2001.

- Figure 4. Articulation of Spanish metropolitan areas in local labor markets (75\% minimum self-containment level).

NOTE: minimum market self-containment is defined as the minimum value of two indicators: supply self-containment (the percentage of employed people resident in the market that work within its boundaries) and demand self-containment (the percentage of jobs that exist in the market that are taken by workers who reside in area).

Source: prepared by authors using commuting data taken from the Census of Population 2001.

- Figure 5. Articulation of Spanish metropolitan areas in local labor markets

(66.7\% minimum self-containment level).

NOTE: see note to Fig. 3 for an explanation of the variable represented.

Source: prepared by authors using commuting data taken from the Census of Population 2001.

- Figure 6. Articulation of Spanish metropolitan areas in local labor markets (females) (66.7\% minimum self-containment level). 
NOTE: see note to Fig. 3 for an explanation of the variable represented.

Source: prepared by authors using commuting data taken from the Census of Population 2001. 
Figure 1

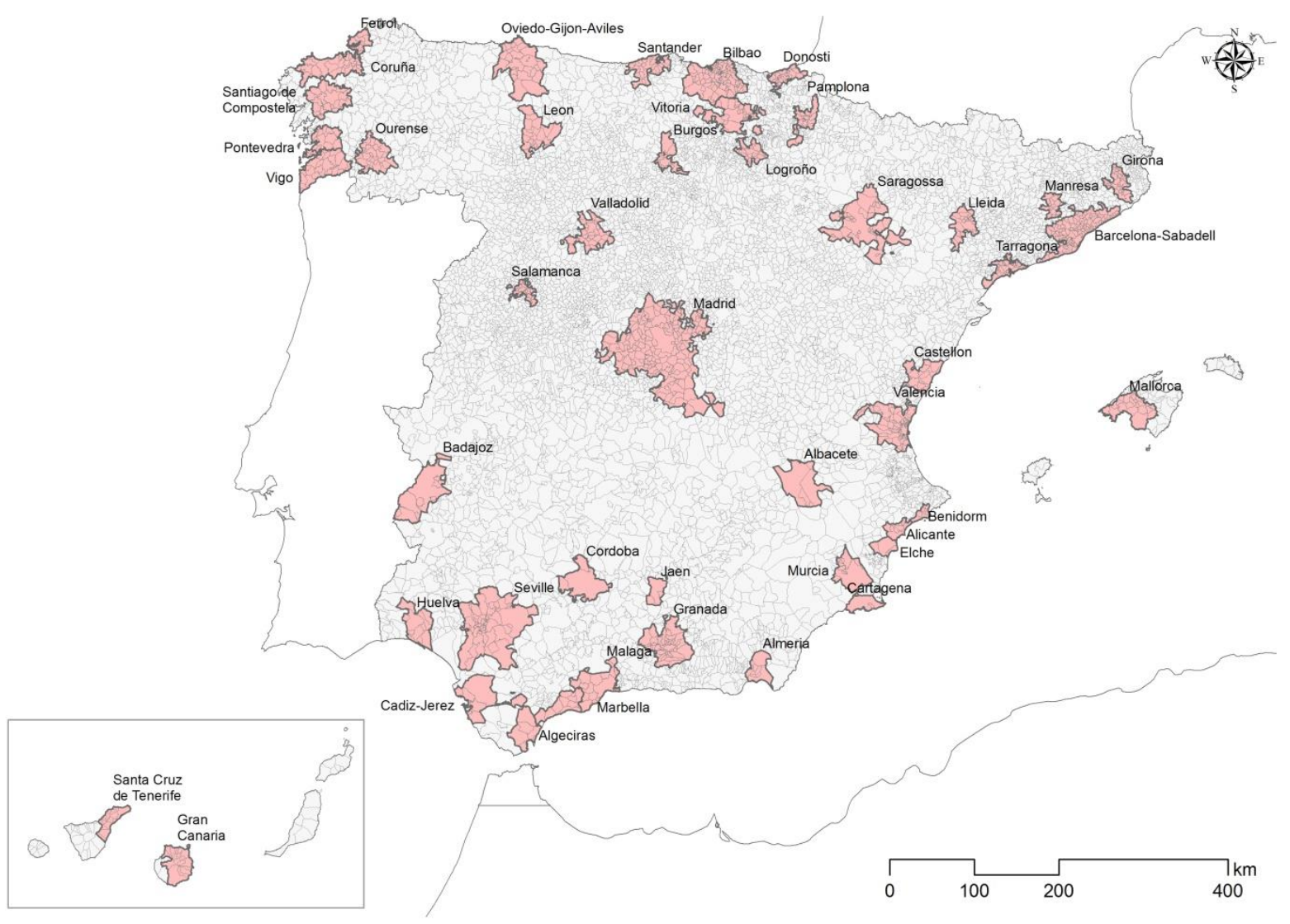


Figure 2

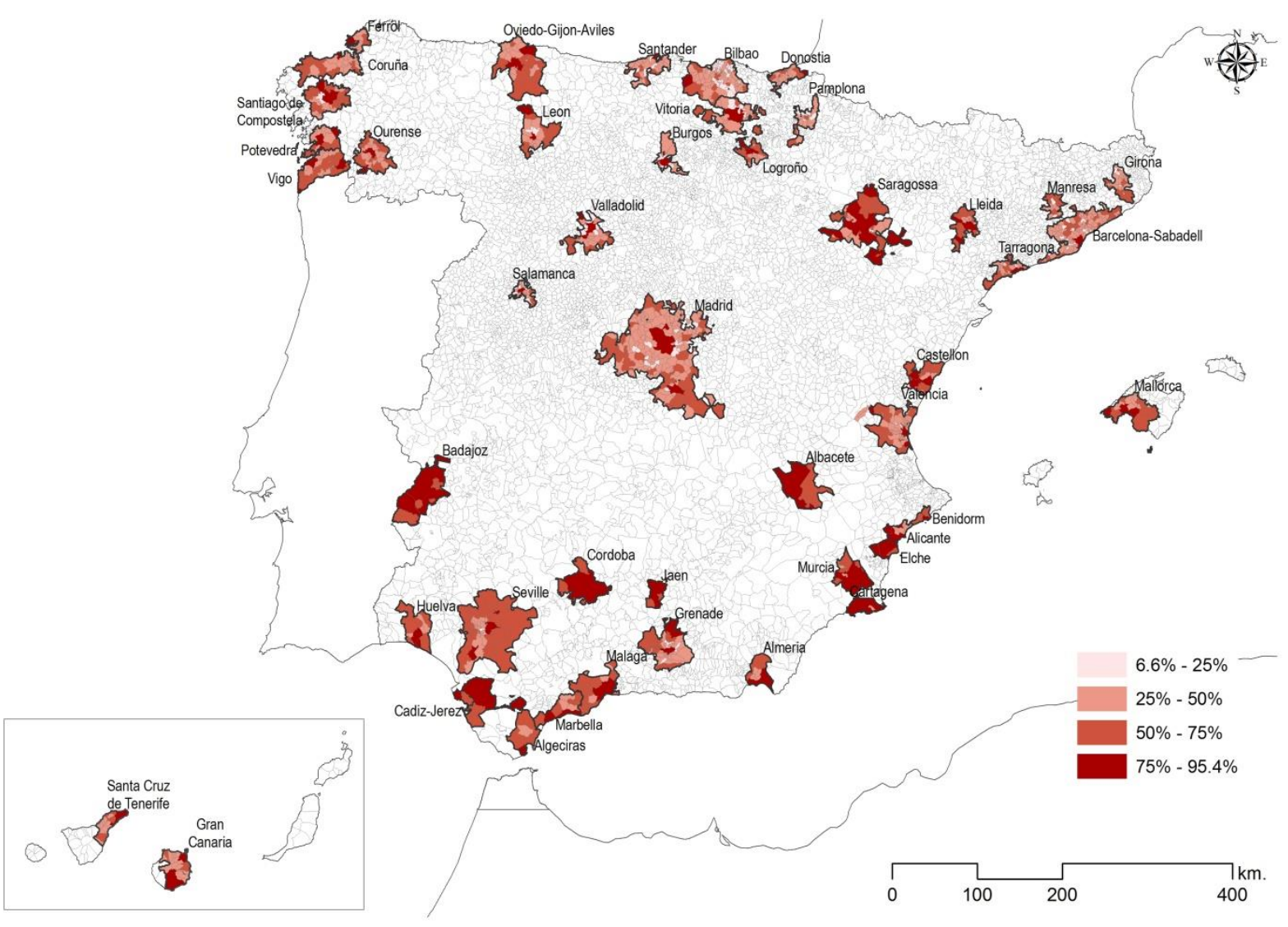


Figure 3

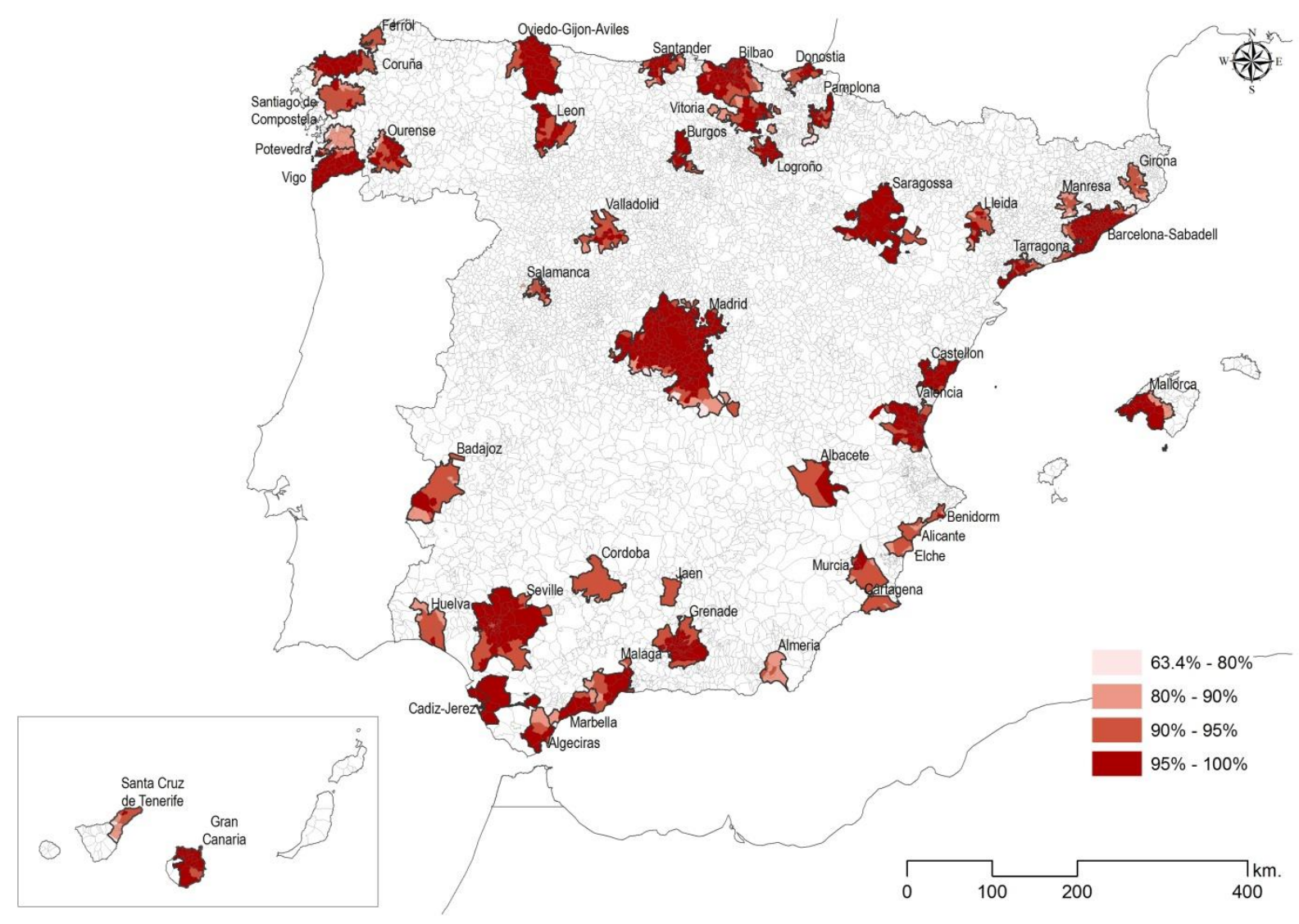


Figure 4

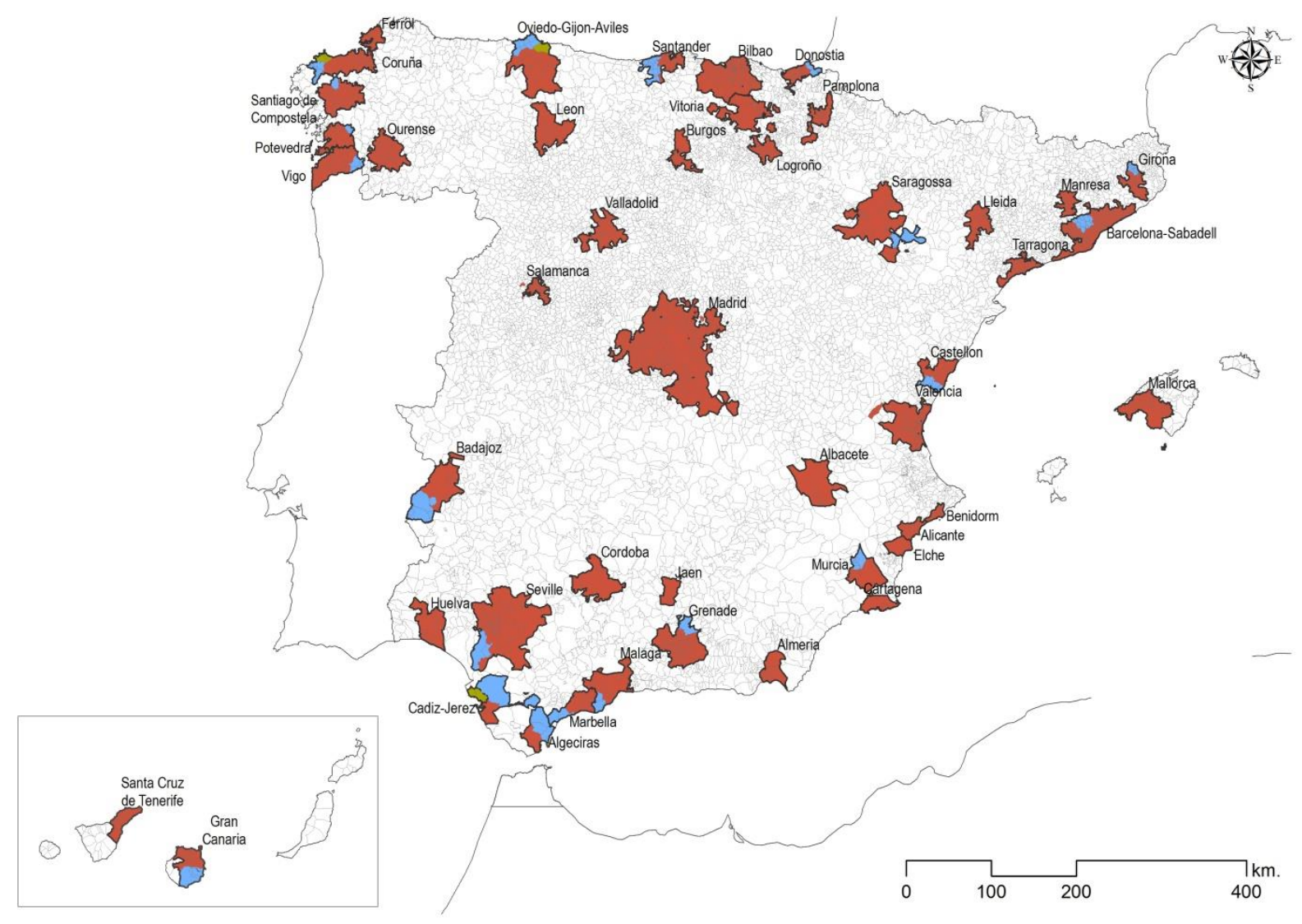


Figure 5

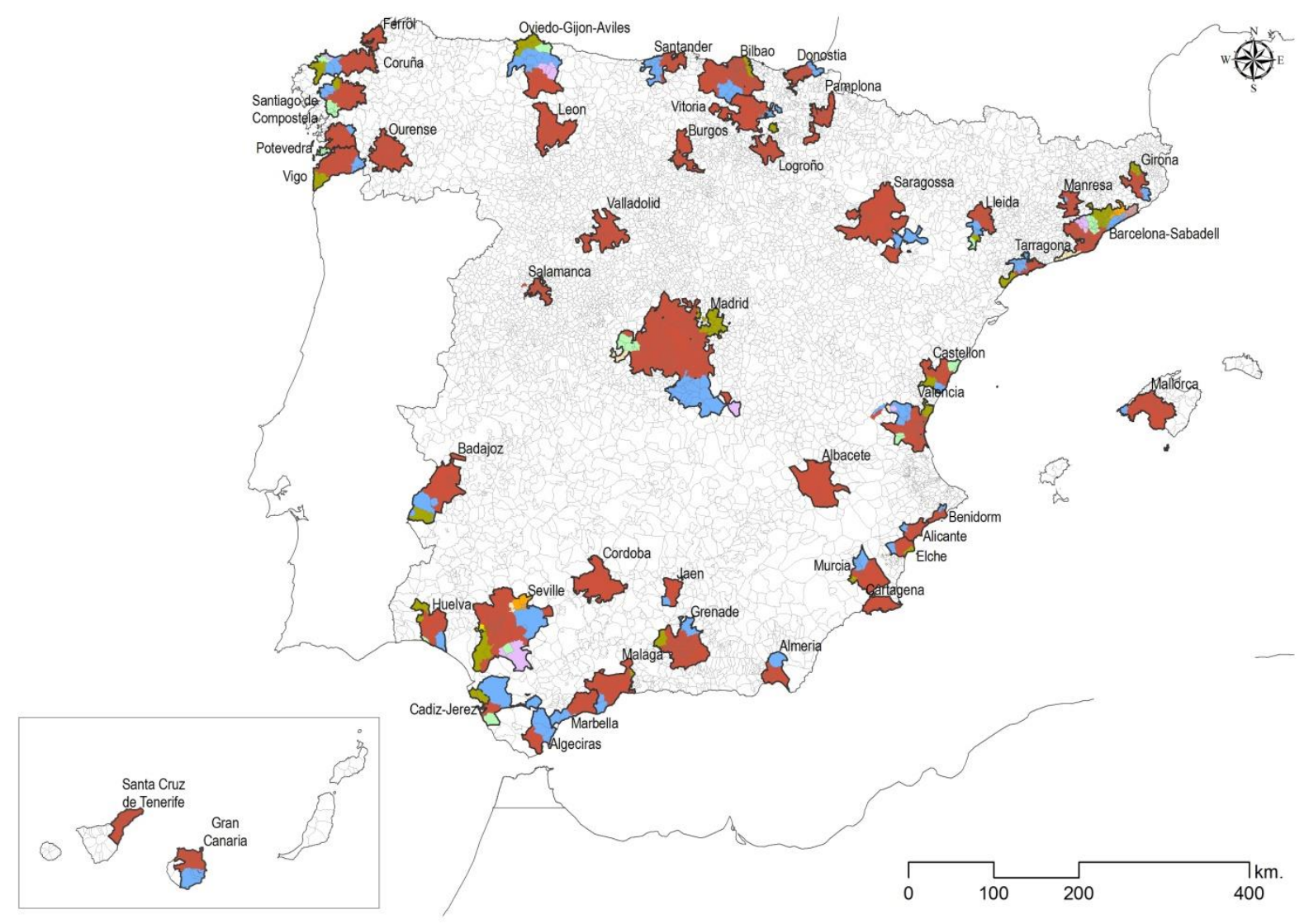


Figure 6

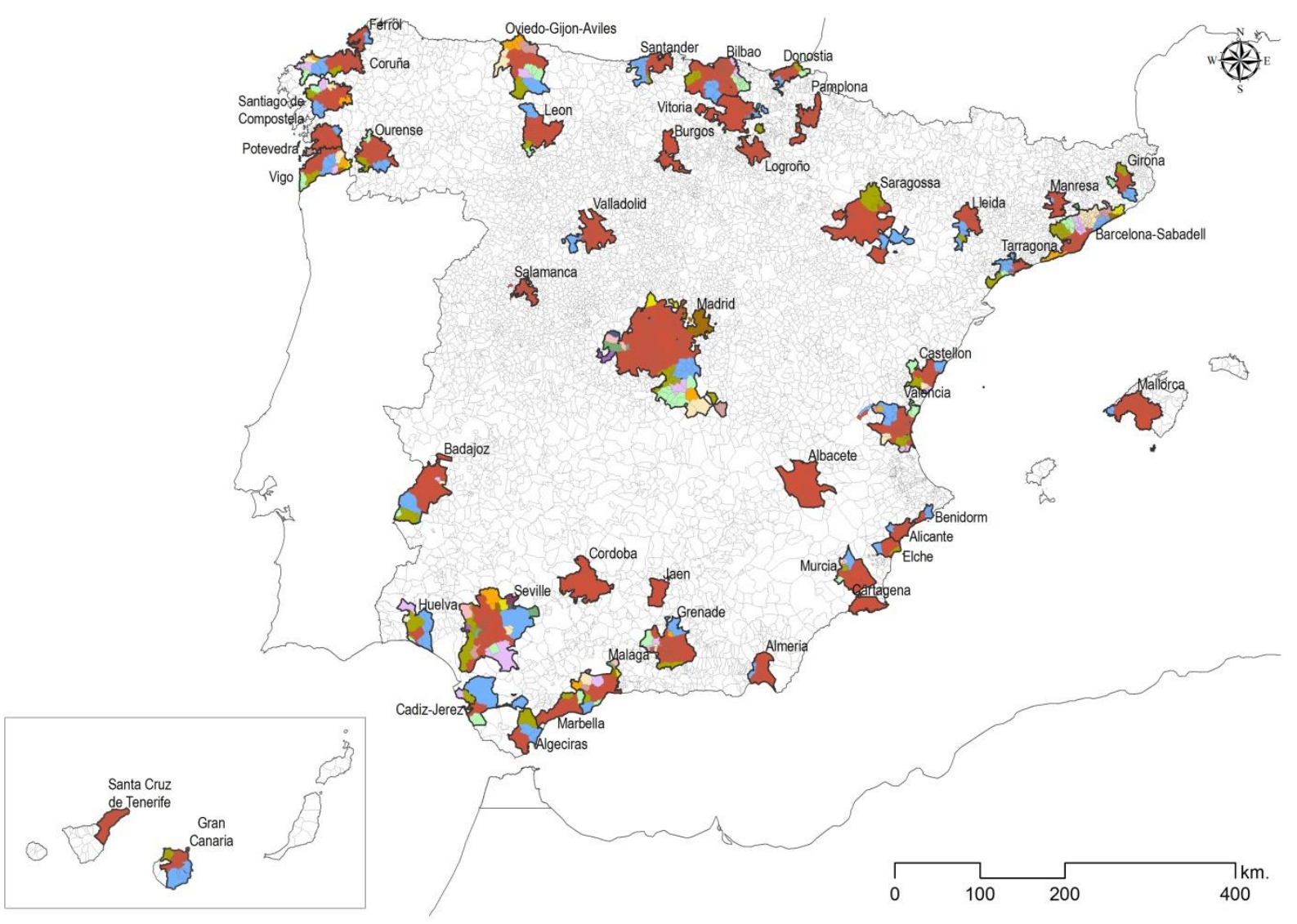


Supplementary material

Detail of the internal structure of the ten main Spanish metropolitan areas (analysis of total population)

\begin{tabular}{|c|c|c|c|c|c|c|c|c|c|c|c|}
\hline \multicolumn{4}{|c|}{ Metropolitan area } & \multicolumn{8}{|c|}{ Local labor submarkets by minimum level of self-containment required } \\
\hline \multirow[b]{2}{*}{ Name } & \multirow[b]{2}{*}{$\begin{array}{l}\text { No. } \\
\text { munic. }\end{array}$} & \multirow[b]{2}{*}{ Employed } & \multirow[b]{2}{*}{$\begin{array}{l}\text { Min. } \\
\text { auton. }\end{array}$} & \multicolumn{4}{|c|}{$75 \%$} & \multicolumn{4}{|c|}{$66.7 \%$} \\
\hline & & & & Name & $\begin{array}{l}\text { No. } \\
\text { munic. }\end{array}$ & Employed & $\begin{array}{l}\text { Min. } \\
\text { auton. }\end{array}$ & Name & $\begin{array}{c}\text { No. } \\
\text { munic. }\end{array}$ & Employed & $\begin{array}{l}\text { Min. } \\
\text { auton. }\end{array}$ \\
\hline \multirow[t]{3}{*}{ Madrid } & 171 & $2,372,980$ & 98.7 & Madrid & 171 & $2,372,980$ & 98.7 & Madrid & 131 & $2,284,347$ & 97.8 \\
\hline & & & & & & & & Guadalajara & 16 & 51,933 & 70.7 \\
\hline & & & & & & & & Aranjuez & 15 & 28,759 & 70.2 \\
\hline \multirow[t]{5}{*}{ Barcelona } & 130 & $1,787,855$ & 98.3 & Barcelona & 119 & $1,586,968$ & 95.4 & Barcelona & 46 & $1,189,753$ & 89.4 \\
\hline & & & & Sabadell & 11 & 200,887 & 76.3 & Sabadell & 12 & 172,055 & 68.1 \\
\hline & & & & & & & & Granollers & 25 & 116,306 & 70.5 \\
\hline & & & & & & & & Terrassa & 6 & 106,852 & 72.9 \\
\hline & & & & & & & & Mataro & 18 & 104,471 & 69.0 \\
\hline \multirow{4}{*}{ Valencia } & & & & & & & & Lliria & 8 & 18,069 & 68.5 \\
\hline & & & & & & & & Turis & 2 & 2,615 & 69.5 \\
\hline & & & & & & & & Villar del Arzobispo & 1 & 1,109 & 77.8 \\
\hline & & & & & & & & Casinos & 1 & 701 & 69.6 \\
\hline
\end{tabular}


Detail of the internal structure of the ten main Spanish metropolitan areas (analysis of total population)

\begin{tabular}{|c|c|c|c|c|c|c|c|c|c|c|c|}
\hline \multicolumn{4}{|c|}{ Metropolitan area } & \multicolumn{8}{|c|}{ Local labor submarkets by minimum level of self-containment required } \\
\hline \multirow[b]{2}{*}{ Name } & \multirow[b]{2}{*}{$\begin{array}{l}\text { No. } \\
\text { munic. }\end{array}$} & \multirow[b]{2}{*}{ Employed } & \multirow[b]{2}{*}{$\begin{array}{l}\text { Min. } \\
\text { auton. }\end{array}$} & \multicolumn{4}{|c|}{$75 \%$} & \multicolumn{4}{|c|}{$66.7 \%$} \\
\hline & & & & Name & $\begin{array}{c}\text { No. } \\
\text { munic. }\end{array}$ & Employed & $\begin{array}{l}\text { Min. } \\
\text { auton. }\end{array}$ & Name & $\begin{array}{l}\text { No. } \\
\text { munic. }\end{array}$ & Employed & $\begin{array}{l}\text { Min. } \\
\text { auton. }\end{array}$ \\
\hline \multirow[t]{10}{*}{ Seville } & 49 & 433,615 & 97.3 & Seville & 47 & 431,272 & 97.3 & Seville & 36 & 382,430 & 94.5 \\
\hline & & & & Isla Mayor & 2 & 2,343 & 78.3 & Utrera & 1 & 11,922 & 73.7 \\
\hline & & & & & & & & Carmona & 2 & 12,554 & 68.4 \\
\hline & & & & & & & & Palacios and V. (Los) & 1 & 10,023 & 72.9 \\
\hline & & & & & & & & Brenes & 2 & 5,638 & 72.1 \\
\hline & & & & & & & & Cantillana & 2 & 3,500 & 68.8 \\
\hline & & & & & & & & Isla Mayor & 2 & 2,343 & 78.3 \\
\hline & & & & & & & & Tocina & 1 & 2,902 & 72.7 \\
\hline & & & & & & & & Benacazon & 1 & 1,746 & 70.3 \\
\hline & & & & & & & & Huevar del Aljarafe & 1 & 557 & 68.8 \\
\hline \multirow[t]{3}{*}{ Bilbao } & 93 & 402,841 & 96.6 & Bilbao & 93 & 402,841 & 96.6 & Bilbao & 78 & 375,830 & 95.4 \\
\hline & & & & & & & & Gernika-Lumo & 8 & 13,177 & 72.9 \\
\hline & & & & & & & & Llodio & 7 & 13,834 & 71.1 \\
\hline \multirow[t]{5}{*}{ Gijon } & 28 & 284,373 & 98.1 & Oviedo & 18 & 143,552 & 87.3 & Oviedo & 10 & 103,210 & 78.4 \\
\hline & & & & Gijon & 1 & 91,256 & 82.4 & Gijon & 1 & 91,256 & 82.4 \\
\hline & & & & Aviles & 9 & 49,565 & 77.7 & Aviles & 9 & 49,565 & 77.7 \\
\hline & & & & & & & & Langreo & 4 & 21,043 & 68.6 \\
\hline & & & & & & & & Mieres & 4 & 19,299 & 72.9 \\
\hline \multirow[t]{3}{*}{ Malaga } & 19 & 275,774 & 95.1 & Malaga & 16 & 237,379 & 93.4 & Malaga & 15 & 236,524 & 93.4 \\
\hline & & & & Fuengirola & 3 & 38,395 & 83.2 & Fuengirola & 3 & 38,395 & 83.2 \\
\hline & & & & & & & & Riogordo & 1 & 855 & 73.8 \\
\hline
\end{tabular}




\begin{tabular}{|c|c|c|c|c|c|c|c|c|c|c|c|}
\hline Gran Canaria & 18 & 262,420 & 97.5 & $\begin{array}{l}\text { Gran Canaria } \\
\text { Santa Lucia }\end{array}$ & $\begin{array}{r}14 \\
4\end{array}$ & $\begin{array}{r}207,752 \\
54,668\end{array}$ & $\begin{array}{l}92.3 \\
77.8\end{array}$ & $\begin{array}{l}\text { Gran Canaria } \\
\text { Santa Lucia }\end{array}$ & 14 & $\begin{array}{r}207,752 \\
54668\end{array}$ & 92.3 \\
\hline
\end{tabular}

Detail of the internal structure of the ten main Spanish metropolitan areas (analysis of total population)

\begin{tabular}{|c|c|c|c|c|c|c|c|c|c|c|c|}
\hline \multirow[b]{3}{*}{ Name } & \multicolumn{3}{|c|}{ Metropolitan area } & \multicolumn{8}{|c|}{ Local labor submarkets by minimum level of self-containment required } \\
\hline & \multirow[b]{2}{*}{$\begin{array}{l}\text { No. } \\
\text { munic. }\end{array}$} & \multirow[b]{2}{*}{ Employed } & \multirow[b]{2}{*}{$\begin{array}{l}\text { Min. } \\
\text { auton. }\end{array}$} & \multicolumn{4}{|c|}{$75 \%$} & \multicolumn{4}{|c|}{$66.7 \%$} \\
\hline & & & & Name & $\begin{array}{c}\text { No. } \\
\text { munic. }\end{array}$ & Employed & $\begin{array}{l}\text { Min. } \\
\text { auton. }\end{array}$ & Name & $\begin{array}{c}\text { No. } \\
\text { munic. }\end{array}$ & Employed & $\begin{array}{l}\text { Min. } \\
\text { auton. }\end{array}$ \\
\hline \multirow[t]{2}{*}{ Saragossa } & 31 & 273,666 & 97.1 & Saragossa & 29 & 271,197 & 96.9 & Saragossa & 29 & 271,197 & 96.9 \\
\hline & & & & Fuentes de Ebro & 2 & 2,469 & 76.9 & Fuentes de Ebro & 2 & 2,469 & 76.9 \\
\hline \multirow[t]{4}{*}{ Cadiz } & 7 & 173,517 & 94.3 & Cadiz & 4 & 89,904 & 88.6 & Cadiz & 3 & 72,026 & 82.8 \\
\hline & & & & Jerez de la Fra. & 1 & 53,105 & 85.3 & Jerez de la Fra. & 1 & 53,105 & 85.3 \\
\hline & & & & Puerto de Sta. M.(El) & 2 & 30,508 & 75.8 & Puerto de Sta. M.(El) & 2 & 30,508 & 75.8 \\
\hline & & & & & & & & Chiclana de la Fra & 1 & 17,878 & 72.3 \\
\hline
\end{tabular}

NOTE: The figures at the top of the columns refer to the minimum level of self-containment required for a group of municipalities to be considered as a local labor market within a specific metropolitan area (rows) (only two of the three scales analyzed are presented in this chart: 75 and 66.7\%). Min. auton. refers to the minimum self-containment: it is the lowest value of two indicators: (a) supply self-containment (the proportion of employed people resident in the area that work within its boundaries) and (b) demand self-containment (the proportion of jobs in the area taken by residents in the area).

Source: prepared by authors using commuting data taken from the Census of Population 2001. 